\title{
A PEDAGOGIA HISTÓRICO-CRÍTICA E OS DESAFIOS FRENTE À EDUCAÇÃO
}

\author{
Helloysa Bragueto Moreira ${ }^{1}$ \\ João Batista Zanardini ${ }^{2}$
}

\section{RESUMO}

O presente artigo é resultado de pesquisas realizadas no Grupo de Pesquisa HISTEDOPRGT região Oeste do Paraná, e também de estudos para a elaboração do Trabalho de Conclusão de Curso de Pedagogia da Universidade Estadual do Oeste do Paraná - Campus Cascavel. Realizamos neste trabalho, uma abordagem que considera a importância da Pedagogia histórico-crítica para a educação escolar, e também a relevância da discussão acerca de seus pressupostos filosóficos, com o propósito de avançar cada vez mais em seus aspectos teóricos e práticos. Intentamos compreender o movimento desta teoria no contexto educacional, mais especificamente no estado do Paraná, tratando minimamente de sua implantação, para que a partir daí fosse possível traçarmos alguns questionamentos, reflexões e angústias que vivenciamos enquanto profissionais da educação, buscando evidenciar a Pedagogia histórico-crítica como teoria contra - hegemônica.

Palavras-chave: Marxismo e Educação; Pedagogia histórico-crítica.

\section{THE HISTORICAL-CRITICAL PEDAGOGY AND THE CHALLENGES FACING THE EDUCATION}

\begin{abstract}
This paper is a result of several researches that have been carried out by the HISTEDOPRGT Research Group in Western Paraná. There were also other studies in order to prepare a Final Written document named as Trabalho de Conclusão from the Pedagogy Course from Western Paraná State University- Campus of Cascavel city. An approach was carried out regarding the importance of Historical-Critical Pedagogy for school education as well as the brainstorming relevance about the philosophical assumptions to advance increasingly in its theoretical and practical aspects. It was aimed at comprehending the movement of this theory in the educational context, more specifically in Parana state, treating minimally of its establishment. So, based on this, it was possible to determine some questions, reflections and our anxieties as education professionals, who have searched to point out the Historical-Critical Pedagogy as a counter - hegemonic theory.
\end{abstract}

Keywords: Marxism and education; Historical-Critical Pedagogy.

\section{Introdução}

A elaboração deste artigo está articulada a pesquisas realizadas no Grupo de Pesquisa HISTEDOPR ${ }^{3}$ - GT região Oeste do Paraná, e também aos estudos para a elaboração do Trabalho de Conclusão de Curso de Pedagogia da Universidade Estadual do Oeste do Paraná - Campus Cascavel ${ }^{4}$. O mesmo tem como objetivo principal compreender e discutir alguns aspectos da Pedagogia histórico-crítica, que tem no professor Dermeval Saviani, um dos seus principais expoentes. 
Inicialmente, as investigações estiveram pautadas numa determinada possibilidade do marxismo e em sua relação com a problemática educacional mais geral e também pedagógica. Partindo dessa ideia, buscamos compreender e explicitar a Pedagogia histórico-crítica, a compreendendo como uma teoria pedagógica de inspiração marxista.

Com esta base, nossos estudos se pautaram no movimento da Pedagogia históricocrítica, em sua abordagem histórica, teórica e prática. Assim, pudemos perceber a importância dessa teoria pedagógica para a educação, e também a relevância da discussão acerca de seus pressupostos filosóficos, com o propósito de avançar cada vez mais em seus aspectos teóricos e práticos.

Para isso, nos propomos a realizar algumas reflexões sobre essa Pedagogia, que se pretende revolucionária.

Nesse artigo, tratamos minimamente de sua implantação no estado do Paraná para que, a partir daí, fosse possível traçarmos alguns questionamentos, reflexões e angústias que vivenciamos enquanto profissionais da educação, sobretudo no que diz respeito à implementação dessa proposta pedagógica.

\section{Pedagogia histórico-crítica}

A teoria pedagógica histórico-crítica, desenvolvida por Dermeval Saviani,emergiu no contexto de abertura democrática do Brasil. Essa corrente pedagógica apresentava a tentativa de compreender os limites colocados pela educação vigente, e, além disso, visava superaras teorias ${ }^{5}$ existentes até então, na busca de uma teoria crítica que tivesse seus princípios norteados pela ideia de transformação da sociedade, por uma educação revolucionária e uma pedagogia contra-hegemônica. O solo histórico dessa pretensão é o processo de reabertura democrática do início dos anos 1980, frente a um país que estava passando pelo início do processo de redemocratização após anos de repressão capitaneados pela ditadura técnico-burocrática e militar iniciados em $1^{\circ}$ de abril de $1964^{6}$.

Essa corrente pedagógica, ora apareceu de forma ativa no cenário educacional brasileiro, ora sua viabilidade de ascendência parece ter sido sucumbida considerando as teorias educacionais adotadas pelos governos então vigentes, sobretudo os de cariz neoliberal.

No estado do Paraná, podemos relativamente afirmar que a Pedagogia históricocrítica teve seus momentos de ascensão, considerando os governos de José Richa (Partido do Movimento Democrático Brasileiro - PMDB) em 1983, Álvaro Dias (PMDB) em 1987 e Roberto Requião (PMDB) em 1991. Não estamos com isso, afirmando que não ocorreram processos de perdas e ganhos, dada a condução do Estado por diferentes posições políticas e ideológicas. Mesmo assim, a mesma esteve presente no discurso do governo, mas sua apropriação pelos profisssionais da educação ocorreu, muitas vezes, de forma fragmentada e inconsistente (BACZINSKI, 2011).

É importante ressaltarmos que mesmo com essas propostas, o Estado não abandona em nenhum momento sua representatividade em relação à classe dominante. Nossa compreensão do Estado baseia-se em Engels, quando afirma o Estado como:

[...] um produto da sociedade, quando esta chega a um determinado grau de desenvolvimento: é a confissão de que essa sociedade se enredou numa irremediável contradição consigo mesma e está dividida por antagonismos irreconciliáveis que não consegue conjurar. Mas para que esses antagonismos, essas classes com interesses econômicos colidentes não se devorem e não consumam a sociedade numa luta estéril, torna-se necessário um poder colocado aparentemente por cima da sociedade, 
chamado a amortecer o choque e a mantê-lo dentro dos limites da ordem. Este poder, nascido da sociedade, mas posto acima dela e distanciando-se cada vez mais é o Estado (ENGELS, s/d, pp. 135-136).

Contudo, naquele período histórico, onde eram assentadas as premissas da Pedagogia Histórico Crítica devido à superação do regime militar ele se coloca como Estado democrático, isto é, defensor dos direitos do povo e de sua liberdade de expressão (BACZINSKI, 2011).

Segundo Baczinski

[...] nesse período destacamos uma tensão e relativos descompassos entre o dito e o feito, pois a implantação da pedagogia histórico-crítica se deu pela apropriação idealista de seus pressupostos e objetivos, pela versão normativa e receituária, pela tática da formação fragmentária estritamente parcial e utilitária. Isso tudo para manutenção do modelo neoliberal de sociedade e educação (2012, p. 38).

O que podemos compreender diante disso é que a Pedagogia histórico-crítica esteve presente no discurso do governo, dando-nos a impressão de que eles estavam agindo em prol de uma educação transformadora, porém as condições materiais para a viabilização dessa teoria pedagógica não ocorreram como era a intenção.

Sobre isso, Orso e Tonidandel afirmam que

De nada adianta, portanto, tornar obrigatória a 'adoção' de uma proposta pedagógica como ocorreu no Currículo Básico do Paraná, por meio do parecer CEE $\mathrm{N}^{\circ} 242$ de 04/10/91, sem que se criem as condições efetivas para colocá-lo em prática. A forma como foi 'adotada', sem se alterar as condições de funcionamento da escola [...] pode manifestar uma forma de dar uma satisfação pública e diante da impossibilidade de resistir ao forte movimento dos educadores naquele momento, fortalecidos pelaslutas contra a ditadura, pela democratização da sociedade. Dito de outro modo, revela uma forma demagógica de defender algo no discurso, mas na prática trabalhar para inviabilizá-la (2013, p. 150).

Após os governos citados acima, no ano de 1995 o Paraná elegeu como Governador Jaime Lerner pelo Partido da Frente Liberal - PFL. Lerner governou o estado por duas gestões, encerrando seu mandato em 2002. Nesse período, a Pedagogia histórico-crítica parece ter sido anulada, e em seu lugar vieram as concepções neoliberais de educação (BACZINSKI, 2012).

$\mathrm{O}$ que estamos denominando de pedagogias neoliberais, diz respeito às iniciativas e/ou propostas oficiais, ou não, que se materializam para a educação, ligadas a ideologia neoliberal, que tem alguns princípios básicos, tais como: mínima participação estatal nos rumos da economia de um país, pouca intervenção do governo no mercado de trabalho, políticas de privatização de empresas estatais, livre circulação de capitais internacionais e ênfase na globalização, abertura da economia para a entrada de multinacionais, desburocratização do estado, leis e regras econômicas mais simplificadas para facilitar o funcionamento das atividades econômicas, e aumento da produção como objetivo básico para atingir o desenvolvimento econômico, a base da economia deve ser formada por empresas privadas, em defesa dos princípios econômicos do capitalismo ${ }^{7}$.

É preciso considerar, entretanto, que, se nos governos que discursavam em prol da concepção de educação pautada no materialismo histórico já existiam problemas para a 
implementação da mesma, devido às razões apontadas pelos autores citados, no governo Jaime Lerner essa possibilidade parece ter sido suprimida ${ }^{8}$.

Ao analisarmos o período seguinte, de 2003 a 2010, onde o Paraná foi governado por Roberto Requião do Partido Do Movimento Democrático Brasileiro - PMDB, podemos observar que as concepções neoliberais de educação foram relativamente ultrapassadas, pois segundo Baczinski (2012), a SEED (Secretaria de Estado da Educação) defendeu uma concepção de professor que se pautava no sujeito que produz seu próprio conhecimento. Também, nesse momento, ocorreu a reformulação das diretrizes curriculares estaduais, que se opunham aos Parâmetros Curriculares Nacionais. (BACZINSKI, 2012).

Porém, colocamos o seguinte questionamento: mesmo com um avanço na educação em relação ao governo anterior, é possível afirmarmos que a teoria pedagógica históricocrítica permeou a elaboração dos documentos no período de 2003 a 2010 no Paraná?

Segundo Baczinski

[...] é possível identificar que a pedagogia histórico-crítica não foi de fato a teoria que fundamentou a reformulação curricular do estado do Paraná no período analisado. Ou seja, a Secretaria de Estado não definiu qual teoria fundamentaria seu trabalho, apenas deixou claro e explícito, nos objetivos do seu trabalho, sua contraposição à teoria da pedagogia das competências e habilidades (2012, p. 42).

Diante da análise realizada em relação à implantação da Pedagogia histórico-crítica no estado do Paraná, nos propomos a refletir sobre alguns aspectos educacionais, no que diz respeito à tentativa de compreender a concepção teórica que permeia essa proposta pedagógica, na busca de que a mesma tenha a possibilidade de acontecer dentro da escola.

Para isso, é preciso ter claro que a escola não é algo que se encontra isolado, isto é, ela está inserida dentro da sociedade, a qual não se pode desconsiderar a existência. Como afirma Orso

[...] a escola e a aprendizagem não são entes, nem relações que ocorrem isoladamente. Os alunos e professores constituem a própria sociedade; os conteúdos são produzidos na e pela sociedade; as condições da escola e do ensino são marcadas pela sociedade. Enfim, a educação não se constitui num trabalho simples que se limita à relação professor/aluno no interior de quatro paredes; constitui-se numa relação complexa, na qual múltiplos determinantes sociais, econômicos, culturais, históricos e políticos interferem $(2012$, p. 30)

Dessa forma, o educador precisa ter essa compreensão, e, além disso, saber a qual sociedade nos referimos, ou seja, a sociedade capitalista, grosso modo, a sociedade onde uns detém os meios de produção e outros vendem sua força de trabalho para sobreviver, sendo assim baseada pela luta de classes.

E ainda mais, o professor deve se reconhecer como um trabalhador que também é explorado ao vender sua força de trabalho.

Ao se reconhecer dessa maneira o professor tem a possibilidade de se conscientizar e perceber a sociedade na qual está inserido. Isso proporciona a realização de seu trabalho de forma intencional, isto é, mediando o conhecimento produzido historicamente.

Nesse sentido, ele tem a possibilidade de provocar o aluno para que o mesmo seja desafiado a perseguir a superação dos conhecimentos espontâneos propiciando a ele uma reflexão sobre esse conhecimento. Logo, estaria criando condições para a socialização do 
conhecimento científico, conhecimento esse que oportunizará ao aluno "pôr em prática os novos conceitos adquiridos [...]" assumindo assim, "o compromisso de usar, em seu cotidiano, esses conceitos com base em suas características essenciais, concretas, não mais do ponto de vista do fenômeno cotidiano empírico [...]" (GASPARIN, 2009, p. 143).

Saviani afirma que a educação é um ato político. Ao fazer esta colocação, o autor se refere à questão abordada acima, de que "a educação é determinada pela sociedade na qual está inserida". Assim, se nossa sociedade é composta por classes antagônicas "a educação serve a interesses de uma ou de outra das classes fundamentais" (2013, p. 26).

Podemos compreender, portanto que

[...] no caso da pedagogia histórico-crítica, uma de suas características fundamentais é que ela se posiciona claramente a favor dos interesses dos trabalhadores, isto é, da classe fundamental dominada na sociedade capitalista. Daí, seu caráter de pedagogia contra hegemônica inserindo-se na luta pela transformação da sociedade atual (SAVIANI, 2013, p. 26).

Nessa perspectiva, é preciso considerar ainda que, temos a árdua tarefa de pensar numa educação transformadora para alunos que em sua grande maioria não estão preocupados e muito menos interessados na socialização do conhecimento. O que resta a nós professores, envolvidos nessa penosa missão de educar nossos alunos? Como nos coloca Orso

Quem diz que damos importância para a educação se os alunos têm de dividir seu tempo com uma intensa jornada de trabalho, se vão para a escola sem comer, se não têm recursos para comprar livros, se não têm tempo para fazer leituras, nem acompanhar os noticiários (ainda que estes sejam carregados de ideologias)? Será suficiente estar de corpo presente na escola? (2011, p. 238).

O que se configura diante dessas indagações, das inúmeras problemáticas em meio ao campo da educação, é um duro e complexo trabalho para nós educadores. Segundo Orso, por muitos anos a escola foi exclusividade da classe dominante, assim cumpria seu papel de servir aos filhos da elite. A partir do momento em que esta foi universalizada, passou a ser "lotada (de crianças)", contudo "foi necessário esvaziá-la em termos de conhecimentos para impedir que se transformasse em instrumento de transformação da realidade, para que não fosse revolucionária" (2011, p. 242).

Diante das considerações apresentadas, podemos nos colocar a refletir sobre a questão da Pedagogia histórico-crítica, pois essa teoria se apresenta sob a forma de transformadora e revolucionária, porém como podemos trabalhar segundo essa proposta pedagógica numa escola que serve aos interesses da classe dominante?

Além do fato de que a escola está situada numa sociedade regulada pelo capital e segundo Mészáros "o capital é irreformável porque pela sua própria natureza, como totalidade reguladora sistêmica, é totalmente incorrigivel" (2008, p. 27), logo esse aspecto reflete-se na escola. Ainda segundo este autor

[...] temos que reivindicar uma educação plena para toda a vida, para que seja possível colocar em perspectiva a sua parte formal, a fim de instituir, também aí, uma reforma radical. Isso não pode ser feito sem desafiar as formas atualmente dominantes de internalização, fortemente consolidadas a favor do capital pelo próprio sistema educacional formal. De fato, da maneira como estão as coisas hoje, a principal função da 
educação formal é agir como um cão de guarda ex-officio e autoritário para induzir um conformismo generalizado em determinados modos de internalização, de forma a subordiná-los às exigências da ordem estabelecida (2008, p. 55).

Nesse sentido, ressaltamos que o professor também tem sua força de trabalho explorada pelo modo de produção capitalista. É necessário que ele tenha consciência disso, pois, "o professor é aquele que prepara os futuros trabalhadores para que 'gentilmente' alienem sua força de trabalho" (FERNANDES; ORSO, p. 33, 2011).

Daí deriva a importância de nós professores conhecermos a Pedagogia históricocrítica, para que possamos ir além da perspectiva de que nos cabe somente "transmitir" conhecimentos, para uma educação que produza "direta e intencionalmente, em cada indivíduo singular, a humanidade que é produzida histórica e coletivamente pelo conjunto dos homens" (SAVIANI, 2003, p. 13).

Ao fazermos essas colocações, não temos a intenção de depositar toda a responsabilidade em relação à educação nos professores, culpando os mesmo pela forma em que a escola se organiza. Também estamos cientes das enormes dificuldades enfrentadas todos os dias por aqueles que têm a tarefa de socializar o conhecimento. Porém, não devemos nos isentar dessa tarefa que escolhemos, mesmo tendo a clareza de que a educação não transformará por si mesma a sociedade, porque "a educação tende a refletir a sociedade que a produziu", é preciso que estejamos firmes nessa luta. (FERNANDES; ORSO, p. 33, 2011).

É a partir desse pressuposto que todos que estão comprometidos e empenhados com o trabalho educativo têm de se pautar, sempre reivindicando por seus direitos na busca de melhores condições de trabalho, porém nunca se limitando somente a isso.

Ainda de acordo com Orso

Em nossa luta, porém, devemos ir trabalhando para congregar, unir e trazer os que, apesar de pertencerem efetivamente à classe trabalhadora, não têm consciência desta condição, para que possamos fazer o movimento de volta e, fortalecidos, conscientes e unidos, possamos imprimir a direção de nossas vidas e da sociedade (2011, pp. 245-246).

\section{Alguns questionamentos...}

Diante dos estudos realizados para elaboração do presente artigo, cabe considerar que a Pedagogia histórico-crítica, no decorrer de sua formulação perpassou por diversos momentos. Isto é, ocorreram etapas em que ela esteve presente de forma mais ativa no contexto educacional, e momentos em que ela foi relativamente refutada em razão dos desafios e interesses que se materializam no campo educacional, e também especificamente, as mudanças de teorias pedagógicas a cada governo, de forma particular no estado do Paraná no período e nos governos citados.

Também podemos ressaltar dificuldades no que diz respeito colocar em prática essa teoria pedagógica, pois partimos do pressuposto de que o desenvolvimento da teoria necessita da realização do caminho inverso, ou seja, a prática precisa ocorrer para que a teoria seja fundamentada. Assim, colocamos em questionamento o desafio da compreensão da concepção teórica que permeia essa corrente pedagógica e também a realização da didática proposta para essa pedagogia. Concordamos com Orso e Tonidandel quando afirmam 
De qualquer modo, ao menos no discurso, a PHC está presente no Estado e na Rede Paranaense de Educação, os professores já ouviam falar dela e está presente nos PPP das escolas. A questão agora é a prática 'espelhar' consequentemente aquilo que está nas ideias, nos discursos e nos PPP, contudo, isto é um pouco mais exigente e complexo ${ }^{9}$ (2013, p. 145).

Além disso, colocamos em questão o problema de carga horária de estudo para os professores, de salário, de salas de aula lotadas de alunos, alunos esses que em sua grande maioria não estão interessados em buscar a socialização do conhecimento produzido historicamente pela humanidade, por razões que muitas vezes fogem do alcance do professor. Alunos que trabalham, que não tem o que vestir, comer ou até mesmo que não tem uma moradia decente, alunos que sofrem violência, que são abandonados pelos pais. Ou seja, referimos alguns dos problemas advindo da base material desses sujeitos da educação, tanto alunos como demais trabalhadores da educação, no sentido de efetivar sua emancipação como seres humanos.

Poderíamos citar inúmeras razões pela qual esses alunos perderam o interesse em apropriarem-se do conhecimento produzido historicamente pelo coletivo dos seres humanos, pois elas existem, e estão presentes, em primeiro lugar na sociedade e refletemse na escola, na sala de aula, no dia-a-dia do professor com o aluno, na relação entre os alunos e destes com a sociedade.

Reiteramos que, o que cabe a nós professores que escolhemos o fazer docente como tarefa diária é estarmos comprometidos com nosso trabalho dentro e fora da sala de aula, conscientes de que não estamos isolados dentro de quatro paredes, porém cônscios da possibilidade que encerra nossa ação.

O trabalho do professor precisa se colocar como algo que desafie o aluno, que o faça buscar um direcionamento político a partir dos conhecimentos científicos, para que seja possível o desenvolvimento das condições de se apropriar do conhecimento produzido historicamente pela humanidade, no intuito de que esse conteúdo tenha um significado para ele, tornando-se um instrumento de luta e de trabalho na busca da transformação social. Sobre isso, Saviani nos diz

[...] os professores tanto podem integrar-se, ainda que não intencionalmente, na luta de classes da burguesia desempenhando o papel de contornar acidentes da estrutura, de impedir que as contradições estruturais venham à tona, de segurar a marcha da história, de consolidar o status quo, quanto podem desempenhar o papel inverso de, a partir dos elementos de conjuntura, explicitar as contradições da estrutura, acelerar a marcha da história, integrando-se na luta de classes do proletariado e contribuindo, assim, para a transformação estrutural da sociedade" (2013, p. 27).

Não estamos aqui, objetivando abordar a educação como responsável pela luta em busca da superação da forma de sociedade existente. Muito pelo contrário, estamos cientes de que a escola serve aos interesses daqueles que detém o poder. Porém, é válido nos conformarmos com esta situação e continuarmos assistindo a forma como a educação é conduzida?

Pensando nisso, é que pesquisamos e discutimos a Pedagogia histórico-crítica, pois se a mesma é uma teoria considerada revolucionária, e nós, enquanto educadores nos preocupamos como a sociedade está organizada e como podemos buscar sua 
transformação, a Pedagogia histórico-crítica vem contribuir com nossa luta. Dessa forma, Saviani afirma que

Considerando, como assinalou Lênin, que é necessário 'assimilar a soma de conhecimentos dos quais é consequência o próprio comunismo' e que a cultura dos trabalhadores deve ser 'o desenvolvimento lógico do acervo de conhecimentos conquistados pela humanidade', a pedagogia históricocrítica colocou, como tarefa precípua da escola, a organização e desenvolvimento do processo de transmissão-assimilação dos conhecimentos sistematizados pela humanidade ao longo da história" (2013, pp. 43-44).

Ao colocarmos um provisório ponto final a este trabalho gostaríamos de deixar claro que não estamos desconsiderando os inúmeros desafios colocados frente à educação, porém, não podemos deixar de lutar em busca de uma educação que vise o acesso a apropriação do "saber sistematizado e não ao saber fragmentado; à cultura erudita e não à cultura popular" (SAVIANI, 2003, p. 14). Nesse sentido, é que colocamos a importância e a indispensabilidade de estarmos comprometidos com essa teoria pedagógica, pois isso implica em um compromisso para com a educação escolar, e a tentativa de lutar em busca da superação dos muitos problemas existentes, visando "assegurar a cada indivíduo aquilo que a humanidade já se apropriou histórica e coletivamente" (MARSIGLIA; OLIVEIRA, 2008, p. 1965).

\section{Referências}

BACZINSKI, Alexandra Vanessa de Moura. A implantação oficial da pedagogia histórico-crítica na rede pública do estado do Paraná (1983-1994): legitimação, resistências e contradições. - Campinas, SP. : Autores Associados, 2011.

. A pedagogia histórico-crítica no estado do Paraná: continuidades e rupturas. In: Pedagogia histórico-crítica: desafios e perspectivas para uma educação transformadora / Ana Carolina Galvão Marsiglia e Eraldo Leme Batista (orgs.). Campinas, SP: Autores Associados, 2012.

FERNANDES, Hélio Clementes; ORSO, Paulino José. O trabalho e a proletarização docente. In: ORSO, Paulino José (Org.). Educação e Sociedade: uma relação desafiadora. Cascavel: EDUNIOESTE, 2011.

GASPARIN, João Luiz. Uma didática para a pedagogia histórico-crítica. - 5. Ed. ver. Campinas, SP: Autores Associados, 2009. - (coleção educação contemporânea).

GERMANO, José Willington. Estado militar e educação no Brasil - 2. Ed. - São Paulo: Cortez, 1994.

MARSIGLIA, Ana Carolina Galvão; OLIVEIRA, Celso Socorro. Aproximações históricas e teóricas com a Pedagogia histórico-crítica e sua proposta metodológica. Disponível

em: $<$ http://www.pucpr.br/eventos/educere/educere2008/anais/pdf/486_560.pdf > Acesso em 01 maio 2014.

MÉSZAROS, István. A Educação para além do capital. São Paulo, SP: Boitempo, 2008. 


\section{MORAES, Reginaldo C. Correa. Liberalismo e Neoliberalismo, uma introdução comparativa. Campinas, SP: 1997.}

ORSO, Paulino José. O Planejamento Escolar em questão. In: Pesquisa, educação e relações sociais/ organizado pó Adrian Alvarez Estrada... [et al.] - Cascavel: EDUNIOESTE, 2012.

ORSO, Paulino José. Por uma educação para além do capital e por uma educação para além da escola. In: ORSO, Paulino José; GONÇALVES, Sebastião Rodrigues; MATTOS, Valci Maria (orgs.). Educação, Estado e Contradições sociais. - 1. Ed. - São Paulo: Outras Expressões, 2011.

ORSO, Paulino José; TONIDANDEL, Sandra. A Pedagogia Histórico-Crítica e o Currículo Báscio para a Escola Pública do Paraná - 1990: do mito à realidade. Germinal: Marxismo e Educação em Debate, Salvador, v. 5, n. 2, p. 144-158, dez. 2013. Disponível em: $<$ http://www.portalseer.ufba.br/index.php/revistagerminal/article/view/9706/7094> Acesso em: 01 maio 2014.

SAVIANI, Dermeval.Pedagogia histórico-crítica: primeiras aproximações - 8. Ed. revista e ampliada - Campinas, SP: Autores Associados, 2003.

SAVIANI, Dermeval. A Pedagogia histórico-crítica, as lutas de classe e a educação escolar.Germinal: Marxismo e Educação em Debate, Salvador, v. 5, n. 2, p. 25-46, dez. 2013. Disponível em: $<$ http://www.portalseer.ufba.br/index.php/revistagerminal/article/view/9697> Acesso em: 01 maio 2014.

\section{Notas}

\footnotetext{
${ }^{1}$ Mestranda do Programa de Pós-Graduação em Educação na Universidade Estadual do Oeste do Paraná.

2 Professor da Universidade Estadual do Oeste do Paraná - UNIOESTE - Curso de Pedagogia. É Doutor em Educação pela Universidade Federal de Santa Catarina (2008), Mestre em Educação pela Universidade Estadual de Maringá (2004).
}

${ }^{3}$ O HISTEDOPR é um grupo de pesquisa em História, Sociedade e Educação no Brasil, com sede na Universidade Estadual do Oeste do Paraná - UNIOESTE -, na Região Oeste do Paraná e está vinculado ao Grupo de Pesquisa em História, Sociedade e Educação no Brasil - HISTEDBR - que tem abrangência nacional e organiza-se por meio de Grupos de Trabalho (GTs) regionais.

\footnotetext{
${ }^{4}$ Apresentado em Setembro de 2013, sob orientação do Professor Dr. João Batista Zanardini.

5 Saviani classifica as teorias educacionais em dois grupos: teorias não-críticas e teorias críticoreprodutivistas. As teorias não-críticas (Pedagogia Tradicional, Pedagogia Nova e Pedagogia Tecnicista) concebem a sociedade como "essencialmente harmoniosa", a educação vem para corrigir o problema da marginalidade, sendo que na pedagogia tradicional marginal é aquele que é ignorante, na pedagogia nova marginal é o rejeitado, e na pedagogia tecnicista marginal é o incompetente (SAVIANI, 2003). As teorias crítico-reprodutivistas (Teoria do Sistema de Ensino como Violência Simbólica, Teoria da Escola como Aparelho Ideológico do Estado e Teoria da Escola Dualista) são críticas pelo fato de conceberem a impossibilidade da compreensão da educação sem considerar seus condicionantes sociais, porém são reprodutivistas porque "chegam invariavelmente à conclusão de que a função da própria educação consiste na reprodução da sociedade em que ela se insere" (SAVIANI, 2003, p. 16).

${ }^{6}$ De acordo com Germano (1994), “o golpe de Estado de 1964 depõe o presidente João Goulart e põe fim à 'democracia populista' iniciada em 1946. Fruto de uma coalizão civil e militar, o golpe configura a ascensão de um novo bloco no poder, que envolver uma articulação entre o conjunto das classes dominantes, ou seja, a
} 
burguesia industrial e financeira - nacional e internacional -, o capital mercantil, latifundiários e militares, bem como uma camada (de caráter civil) de intelectuais e tecnocratas. $\mathrm{O}$ espectro de interesses representados por esse conjunto autoriza-nos a qualificá-lo como uma elite" (p. 17).

${ }^{7}$ A esse respeito ver entre outros, MORAES (1997).

${ }^{8}$ Em relação ao período do governo Jaime Lerner, está em desenvolvimento a pesquisa de Mestrado sobre a problemática da Pedagogia histórico-crítica no referido período, sob orientação do professor Dr. Paulino José Orso.

${ }^{9}$ Sobre esta questão ver Orso e Tonidandel (2013): “A Pedagogia Histórico-Crítica e o Currículo Báscio para a Escola Pública do Paraná - 1990: do mito à realidade”. 